\title{
Psychological Readiness for Marriage as Personal Formation
}

\section{Irina Konstantinovna Kashirskaya}

Candidate of psychological Sciences, associate Professor of the Southern Federal University

Rostov-on-Don; k_irinak@mail.ru

\section{Svetlana Vasilievna Zholudeva}

Candidate of psychological Sciences, associate Professor of the Southern Federal University Rostov-on-Don; ZholudevaSV@yandex.ru

\section{Natalia Evgenievna Skrynnik}

Candidate of psychological Sciences, associate Professor of the Southern Federal University Rostov-on-Don; nckrynnik@yandex.ru

\section{Doi:10.5901/mjss.2015.v6n6s1p452}

\section{Abstract}

In the article the issue of psychological readiness for marriage is raised. On the basis of the theoretical analysis a multicomponent model of psychological readiness for marriage is developed and proved. The author's concept is introduced where psychological readiness for marriage is personal formation the basic system components of which are value orientations, marriage motivation, ideas of marital hierarchy, marital attitudes and expectations, ideas of marital relations. For empirical evidence of the hypothesis made by us the postulation has been taken that any system has a number of attributes, and one of them is an interrelation of separate elements of the system. By means of the methods of mathematical statistics correlation matrices have been obtained which contained multiple significant both positive, and negative relations between the parameters included into the research. The analysis and interpretation of the data obtained in the research is provided.

Keywords: psychological readiness for marriage, components of psychological structure of readiness for marriage, value orientations, marriage motivation, marital hierarchy, marital attitudes and expectations, marital relations.

\section{Introduction}

In the psychological literature such concepts as psychological readiness for parenting (Ovcharova R.V., etc.), psychological readiness for motherhood (Meshcheryakova S.Yu., Ovcharova R.V., Philippova G.G., etc.), psychological readiness for fatherhood (Ovcharova R.V., Demchuk N.A., Spivakovskaya A.S., etc.) have been widely studied. But psychological readiness for marriage has been understudied.

The theoretical analysis of the studies devoted to the issue of readiness for marriage showed that for determination of readiness of a person for family life and marriage such concepts as "readiness for marriage", "ability to marriage", "need for starting a family and upbringing of children", and others are used. As a whole in a number of studies readiness for marriage and starting a family is interpreted as a quality defining the attitudes for marriage and family relations, as the background of starting a family and control of family relations, as an active state of the personality causing activity for organization of marriage and family relations, as a result of family education, psychological preparation and psychological mobilization. Thus, readiness for marriage is complex multi-component personal formation and it is necessary to build a model of readiness for marriage which would include the components of this readiness.

\section{Research Model}

In our research under psychological readiness for marriage we understand personal formation the basic system components of which are value orientations, marriage motivation, ideas of marital hierarchy, marital attitudes and expectations, ideas of marital relations (Figure 1). 


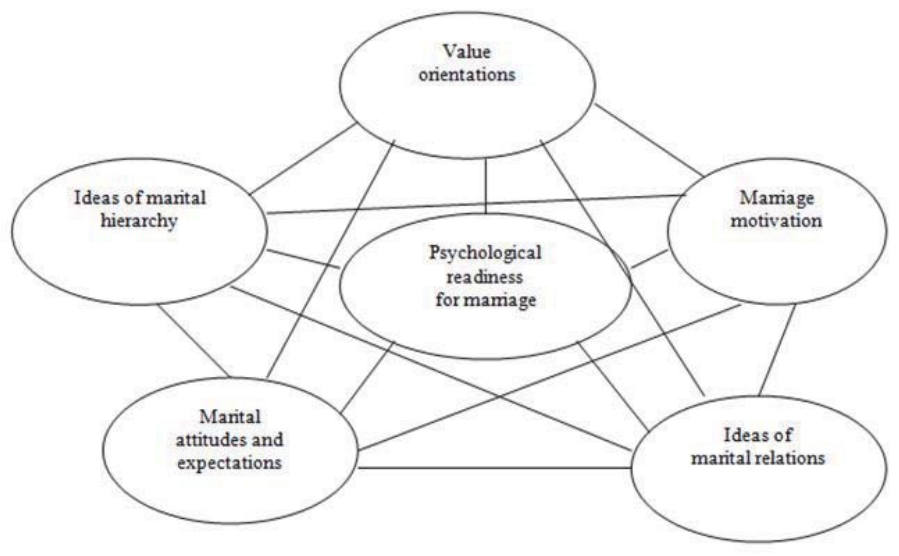

Figure 1. Model of psychological readiness for marriage

The choice of these components is not accidental. Marital values are ideals, ideas of marriage, its peculiarities which are approved and cultivated between the spouses, as well as serve as an important factor of regulation of their relationship. Nation-wide values can find reflection in marital relations. In particular marriage communication can be a source of formation of the values promoting adaptation and socialization of youth.

One may speak about psychological readiness for marriage relations only in the presence of the basis for marriage that is at formation of the motives of building-up of the marital union. The marriage is induced by the system of the motives forming certain hierarchy within which one may speak about the sense-making motives and incentive motives.

The component of ideas of marital hierarchy characterizes the dominance-submission relations in a family, role family structure being an important component in family hierarchy.

The component of marital attitudes and expectations includes the attitudes in relation to the partner and to the person himself, as a marriage partner, and the qualities necessary for marriage, convictions in priority of certain qualities necessary for marriage.

The ideas of marital relations are one of the components of the model of psychological readiness for marriage. Formation of intra-family communication assumes solution of the following tasks: 1) establishment of interaction rules between the spouses; 2) family delimitation, i.e. separation of the family from the fact that is not included into the family.

\section{Research Methodology Literature Review}

So, P. Gerstmann distinguishes two types of goals as a part of the life plan: final (ideal) and secondary (real, concrete). Thus, P. Gerstmann directly points to connection of the life plan with the values. A.A. Grachev says that life orientations of a person are determinants of his life activity (Grachev, 1999).

The idea of the personal future is connected with the values. The values, being socio-historical by nature, are means of inclusion of an individual to the human kind (patrimonial human abilities), thereby, enabling to overcome finiteness (temporality) of human existence. The values, in their turn, are closely connected with the idea of meaning of life which is both the basis of development of the personality, and its result at the same time (Studia Filozoficzne. W-wa, 1981).

Therefore at the solution of the issue of psychological readiness for marriage the system of values which the person adheres to, is of great importance. The classification of values of M. Rokeach who divides them on terminal and instrumental is known (Rokeach, Beliefs, Attitudes and Values, 1968).

The results of many studies (Andreeva, 1985; Antonyuk, 1992; Lisovsky, 1996; Kunitsina, 2004; Moskovicheva, 2000; Yadov, 1979, etc.) show that a family is one of the leading values for young people. It has been established that happy family life along with love takes the main place in the hierarchy of values. Gender differences have been revealed in the choice of these values.

Social maturity and economic independence in today's conditions come much later therefore marriage value in the system of common cultural values of a person is formed late enough. Original sense and meaning of the indicated values 
are open to a person only when he gains sufficient life experience.

Various requirements are imposed both to men, and to women. But the specifics of the current situation is manifested in the fact that a man's marriage is associated mainly with his ability to provide normal living conditions (material and housing), and the desire of women (girls) is often limited to the role of a housewife, i.e. the preference to self-realization variant out of the professional area. The image of a wife is often associated with a parental role but the same cannot be said for the role of a husband (Chistyakova, 1989).

Thus, value orientations are an important life guiding line of the personality defining his activity. Value orientations as a component of the system of psychological readiness include the peculiarities of hierarchy of life values of the personality, their stability, consciousness and level of realization.

Motives of marriage realize vital relations of the personality to the world; make the basis of hierarchy of human needs reflected in the famous Maslow's hierarchy of needs (Maslow, 1970):

- realizing the need to love and to be loved by the partner;

- self-affirmation and self-realization (in particular, motives of social and status affirmation); an aspiration of a young man to leave from the guardianship of his parents by means of starting of his own family can be an example of such motive;

- satisfying the need for feeling of safety when the partner is considered as a source of care, support and stability; in these cases he acts as a peculiar substitute of the parent;

- realizing the need for affiliation;

- motive of self-actualization through division of identity in relations with the significant Other;

- motive of generation continuation, aspiration to realization of the parental role;

- sexual instinct to the partner and desire to have stable sexual relations;

- motive of duty and social obligation which is based on care and responsibility for well-being of the partner;

- pragmatic motive (improvement of living conditions, financial position both own, and grand parental family by means of the partner).

It is obvious that the degree of adequacy of motives for starting of a harmonious family is far not equivalent, and the destiny of newly marriage is to a large extent, though not fatally, defined by the content of motivation of its conclusion (Myers, 2006).

Importance of correlation of motives when choosing a marriage partner is emphasized by a number of researchers. So, N.F. Fedotova and L.A. Philippova specify among the motives of searching of a marriage partner: aspiration to sexual intimacy, desire to take care (these motives are more often noted by men), desire to feel care (it is more often noted by women), desire to love and to be loved (more often concerning women), aspiration to find a similar person, desire to be understood.

Z.I. Feinburg brings marriage motivation to three main reasons: biological, socio-cultural and economic. The famous sociologist S.I. Golod singles out 5 groups of marriage motives: love, spiritual kinship, material benefit, psychological adequacy, moral reasons (Golod, 1990). N.G. Yurkevich considers that people can be married without love, and, therefore, the duty in provision of psychological attitude on family preservation plays an extremely essential role (Yurkevich, 1971).

The general motivation of a family union, according to S.V. Kovalev, includes four leading motives: economichousehold, moral-psychological, family-parental and intimate-personal (Kovalev, 1988).

E. Tiit singled out three groups of marriage goals: joint upbringing of children, development of spouses as persons (including hobbies at leisure and intensive and informative intra-family communication), and creation of own home with giving originality and coziness to it (llyin, 2000).

E.G. Eydemiller and V. Yustitskis singled out the following motives: escape from parents, obligation (marriage because of a sense of duty), loneliness, following the traditions (upon an initiative of parents), love, prestige, search of material benefits, revenge (Eydemiller, Yustitskis, 2002).

K.R. Konistyanskaya and N.V. Osetrova established that motivation of behavior of people in the area of a family formation represents a complex system of subjective factors influencing both on readiness to marry, and on decision to refrain from this step. N.I. Oliferovich, T.A. Zinkevich-Kuzemkina, T.F. Velenta also note that there can be an inadequate motivation of marriage. An inadequate motivation of marriage can be conscious and unconscious (Oliferovich, ZinkevichKuzemkina, Velenta, 2006).

N.V. Malyarov singles out three significant levels of marriage motivation: 1) marriage motivation in general (a spouse considers a family as a socially and personally significant institution for him); 2) motivation on a concrete type of marriage (a spouse forms certain ideas about the fact what should be a family, what are the roles and the responsibilities 
of a husband and a wife, a father and a mother, etc.); 3) motivation on marriage with a concrete person (during family life individual and personal peculiarities and qualities of a spouse are admitted, highly appreciated and taken into consideration) (Malyarov, 1981).

Marriage motives significantly depend on a social status of a subject, his sex, age, available values of life and other factors.

Thus, marriage motivation is an important component and formation of its components in many respects determines the level of psychological readiness for marriage as the more completely and the more precisely a person realizes his motives, the stronger his power over his own actions is.

The following component singled out by us is an idea of marital hierarchy. The hierarchy characterizes the dominance-submission relations in a family. However the term "hierarchy" cannot be limited to this simple definition as it includes the characteristics of various aspects of family relations: authoritativeness, dominance, extent of influence of one spouse on another, the power to make decisions. The concept "hierarchy" is also used in studying of changes in the structure of roles and rules in a family (Chernikov, 2001).

For determination of a form of domination in a family such functions as material support, family budget planning, "psychotherapeutic" function of a family, upbringing of children are priority. The actual domination depends on distribution of functions in a family and degree of participation of its members in the solution of problems. However along with the actual domination there is also formal domination, i.e. attributed by certain rules. In case of divergence of the actual and the formal domination conflicts take place, fight for recognition of the actual management, for establishment of domination of one of family members.

The dominance-submission relations in a family can be characterized in the following parameters: 1) who exactly dominates in a family; 2) bases (reasons) of dominance; 3) transitivity degree of dominance-submission relations; 4) whether dominance also assume taking the responsibility by the dominant person.

The role structure of a family is an important component in family hierarchy. So, family roles are stable functions of the family system fixed to each of its members. The role structure of a family orders to its members what, how, when and in what sequence they should do, interacting with each other. There are rules, instructions concerning both acceptance of roles, and their performance (Minukhin, Fishman, 1998).

In the role structure of a family a plan of conventional and a plan of interpersonal roles are singled out. The role structure of a family provides its effective functioning and satisfaction of the needs of all its members taking into account the following requirements: 1) role coherence; 2) performance of a role should provide satisfaction of the needs of the personality within a family; 3) the accepted roles should correspond to the capabilities of the personality; 4) performance of the roles should provide satisfaction of the needs of all family members.

Acceptance of family roles is considerably defined by the family structure in a parental family, sibling relations, influence of peculiarities of both motivation-need, and value-sense areas of family members and their personal peculiarities.

Four main types of role distribution are singled out: patriarchal, matriarchal, co-leadership, fight for power.

In modern society, in parallel with traditional marriage, there are non-traditional marriages, alternative styles and forms of marriage. The nature of distribution of obligations according to their performance between the spouses is the basis for division of families on traditional and egalitarian. Besides in traditional marriage the roles and the obligations can be rigidly distributed under the mutual agreement or according to the norms specified by the gender roles (Suslova, 1999).

Thus, the traditional role structure of a family assumes fixing of certain roles to spouses according to their gender. (Antonyuk, 1999; Aleshina, 1987; Gozman, 1987; Dubovskaya, 1987; Olisaeva, 1999).

Another approach to systematization of the roles and the role structures corresponding to them is shown by $\mathrm{S}$. Kirkpatrick. He singles out traditional, friend and partner roles (Kirkpatrick, 1955).

E.M. Rollings and F.I. Nye consider the participation of a woman in material support of a family as a criterion of traditional/egalitarian character. Thus, L. Haas has found out that for egalitarian distribution of roles not so much the fact of work of a wife, as her earnings and prestige of her occupation is important (Aleshina, 1987).

Thus, the dominance-submission relations in a family, dominance nature and distribution of roles in general define marriage type, characterizing hierarchy of relations between the spouses.

The component singled out by us is marital attitudes and expectations. There are various theories of a choice of a marriage partner. For example, K. Melville (Melville, 1977) says that it is some kind of "transaction" in which social origin, economic position, education and personal qualities serve as "currency". Supporters of the homogamy theory (Nye F.I., Berardo F.) consider that in this "transaction" not any men and women, but only those who have "social value" can be exchangeable. The theory of "complementary needs" is concluded in the assumption that the principle of homogamy can 
be applied only to socio-cultural characteristics. In the instrumental theory (Centers, 1975) special attention is paid to satisfaction of the needs, i.e. a person is attracted by a person whose needs are similar. According to V.V. Adams the process of a choice passes some stages from attraction based on visual appeal and to studying of values and views of each other. The author of the theory "stimulus-value-role" (Murstein) is based on two premises: the first one, development of relationship of partners depends on equality of exchange, the second one, a choice includes consecutive stages. In "circular love theory" the stages from establishment of interrelation to realization of basic needs of the personality are considered.

Many researchers (Zatsepina V.I., Andreeva T.V., etc.) point to a number of peculiarities which characterize attitudes and expectations concerning marriage and a partner. So, at the age of 13-15 years old there is a progressing division and opposition of the concepts of love and marriage. There is obvious "pushing off" of love in marriage against its previous absolute power (Andreeva, 2007).

Now the priority of personal qualities of a partner, but not social characteristics at the choice of a spouse is observed. T.V. Andreeva has established that a considerable part of girls puts forward a full set of all theoretically possible qualities of a person - from beauty, mind, strong will and fine properties of character to financial prosperity. Thus, many requirements are expressed very categorically; their basic meaning is reduced to the expression "he should put my interests in the center of his life". Dissatisfaction at least of a part of these expectations in marriage leads to breach of relations, despite the presence of children (Andreeva, 1989).

E.G. Eydemiller and V.V. Yustitskis write that the wrong choice of a partner is often connected with the expectations that a husband/a wife will remind a father/a mother. In a love match not the real assessment of an emotional component, but the exaggerated sexual imaginations sometimes prevail.

Ideas of marital relations. Establishment of the interaction rules between the spouses includes: 1) establishment of distance in communication or degree of emotional proximity accepted for both members of a couple; 2 ) development of ways of conflict solution in case of disagreement of the spouses with each other.

Determination of an optimal distance in communication depends on the ability of each partner to find his/her own limits. Before uniting and creating a couple, each person should find his/her own "self". In E. Erikson's terms it is called to create mature identity. Another variant of interaction is "merging" with a partner thanks to whom he/she unconsciously tries to strengthen his/her own "self" (Eydemiller, Yustitskis, 2002).

Before the spouses there is also a problem of how "naturally" they should behave with each other. It is usually transformed to the problems of whether it is necessary to make any efforts in order to look better (for example, how to put on at home, whether to put on make-up), whether it is necessary to adhere to some ceremony in behavior (to help on with the coat, to let pass at entrance), whether it is necessary to try to hide the bad mood, etc.

The next important task is development of the ways of conflict resolution (Posysoev, 2004). Establishment of the interaction rules and development of the ways of conflict resolution form the style of emotional communication - the way of communication in a family which is characterized by certain correlation of positive and negative emotions, criticism and praise to each other, including also presence or absence of prohibition on public expression of feelings (Oliferovich, Zinkevich-Kuzemkina, Velenta, 2006).

For description of relationship between a family and social environment (external limits), as well as between various subsystems inside a family (internal limits) the parameter "family limits" is used. Each family develops its own rules, and the limits of families have unequal flexibility and permeability.

For a young couple delimitation of a family means first of all redefinition of their relations with parental families. Now the roles of a son and a daughter should become secondary, yielding to the roles of a husband and a wife.

Thus, at the initial stage of existence of a family the formation of emotional bonds, communication style in a family means development of the interaction rules between the spouses, i.e. finding the degree of their emotional proximity and the ways of conflict solution and delimitation of a family, i.e. the interaction rules of a family with the external world on the basis of those ideas of marital relations which have developed before.

\section{Empirical Analysis and Hypothesis Testing}

For empirical testing of our theoretical assumptions that psychological readiness for marriage is personal formation the basic system components of which are value orientations, marriage motivation, ideas of marital hierarchy, marital attitudes and expectations, ideas of marital relations, the postulate was taken that any system has a number of attributes, and one of them is an interrelation of separate elements of the system. So, the main task of the empirical research was the study of psychological readiness for marriage as a system. For solution of this task the method of correlation analysis for identification of statistically significant correlation communications between the components and within them was 
chosen. For realization of the set task all diagnostically significant parameters were grouped according to the components of psychological readiness for marriage. The assigned task of the research required detailed selection of diagnostic tools, therefore our preferences were given to those methods which allowed to receive simultaneously the most various range of information on the studied peculiarities of the singled out system components of psychological readiness for marriage and to establish interrelation between them.

For solution of the research tasks the following methods were used: "Interaction of Spouses in a Conflict Situation" (Aleshina Yu.E., Gozman L.Ya., Dubrovskaya E.M.), questionnaire "Attitude Measurement in a Married Couple" (Aleshina Yu.E.), A.N. Volkova's questionnaire "Role Expectations and Aspirations in Marriage", E.B. Fantalova's method, an author's questionnaire - "Motivational Readiness for Marriage", an author's questionnaire "Ideas about Me and the Marriage Partner". Author's questionnaires have passed the analysis on constructive and criterion (empirical) validity, reliability by means of Cronbach's alpha reliability factor and test-retest reliability and conform to the specified requirements.

In total 422 persons aged from 17 to 60 years old took part in the research. We grouped the respondents of the sample in two groups. Group 1 - the people getting married for the first time (122 persons), Group 2 - the people who are not going to marry in the nearest time (300 persons). The correlation analysis was carried out in two groups one by one on each component.

It should be noted at once that the obtained correlation matrices contained multiple significant both positive, and negative communications between the parameters included into the research. We rest upon the analysis and the interpretation only of those of them which seem to us the most significant for realization of the research goals.

We will describe the significant correlation relationships between the parameters within the component value orientations in Group 1 (Figure 2).



Figure 2. Correlation pleiade of the parameter "love" (of the component value orientations) with other parameters of this component

The obtained data show that if love is of value for a person, then he feels the need for joining up with the partner, wishes close and trust relations, wants the performance of parental function together with the partner in the future. And thus he rejects for himself independence and distance from the partner, which is confirmed by the negative correlation relationships with such life values as freedom and self-confidence (moral certainty), with family activity areas such as intimate and sexual and visual appeal. 


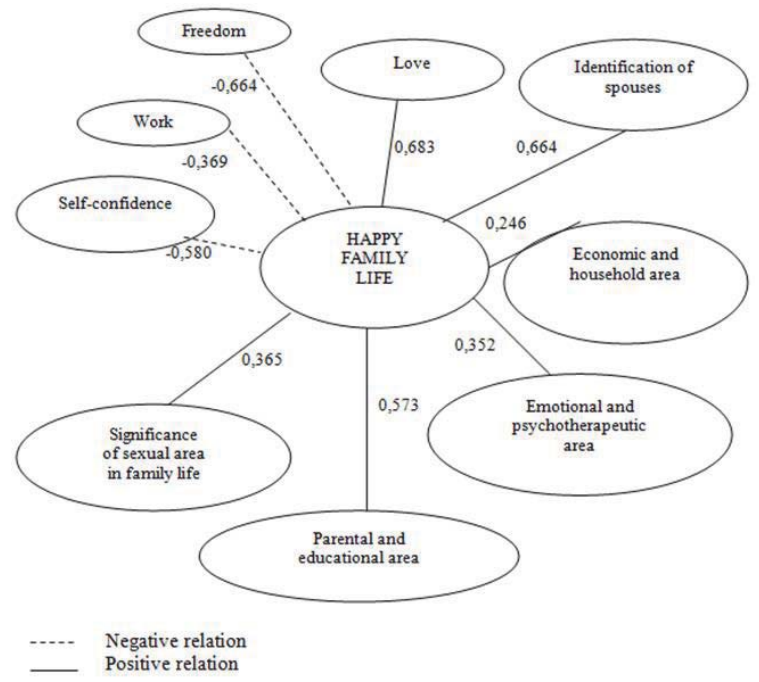

Figure 3. Correlation pleiade of the parameter "happy family life" (of the component value orientations) with other parameters of this component

Correlation relationships of the parameter happy family life has shown (Figure 3) that the happy family life is formed on the basis of love, thus, the sexual area is of great importance, but not basic as the significant correlation relationship is found with the parameter identification with a spouse and emotional and psychotherapeutic function of a family. Relations with such life activity areas of a family as economic-household and parental-educational is also revealed.

We explain that by the fact that marriage in the future assumes the performance of parental function and household duties. Negative correlation relationships of the parameter happy family life are found with such values as work, freedom as independence in deeds and actions, self-confidence as moral certainty. As you can see by the obtained data, the negative correlation relationships of the parameter "love" practically coincide with the negative correlation relationships of the parameter "happy family life".

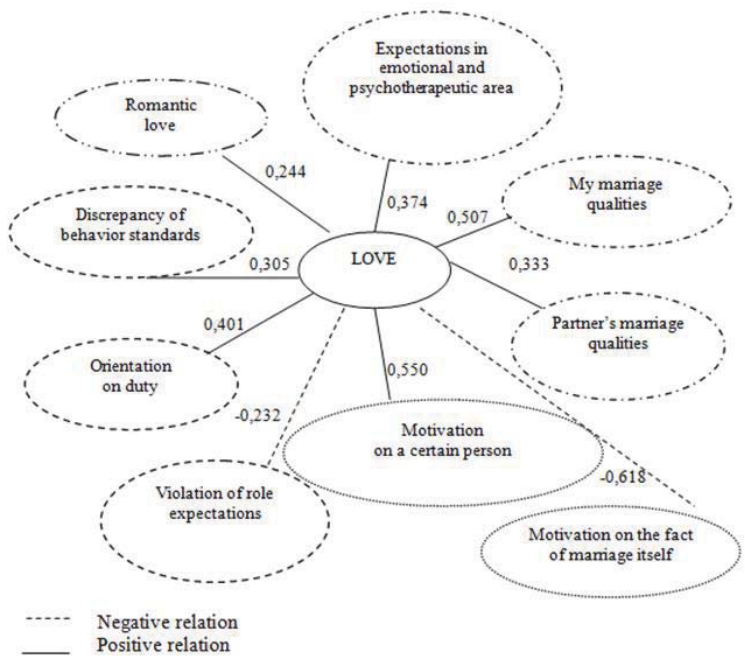

Figure 4. Correlation pleiade of the parameter "love" (of the component value orientations) with other parameters of the components of psychological readiness for marriage 
It gives the ground to conclude that people, when getting married, as a rule, think that freedom, independence in deeds, excessive self-confidence are those qualities which badly affect the family happiness while harmonious sexual life, identification of spouses, emotional and psychotherapeutic, parental and educational, economic and household life areas promote the formation of harmonious family relations.

The component value orientations of the system of psychological readiness for marriage has significant correlation relationships and with each component of the system of psychological readiness for marriage (marriage motivation, marital hierarchy, marital attitudes and expectations, marital relations) (Figure 4). So, the correlation analysis of the parameter love and happy family life allowed discovering its interrelation with the parameters not only within the component, but also with the parameters of other components.

Table 1. Correlation analysis within the component marriage motivation

\begin{tabular}{|l|c|c|c|}
\hline Motivation & Motivation & $\begin{array}{c}\text { Motivation on a certain type } \\
\text { of marriage }\end{array}$ & $\begin{array}{c}\text { Motivation on the fact of } \\
\text { marriage itself }\end{array}$ \\
\hline Motivation on a certain person & - & $\begin{array}{c}r=-0,234 \\
p<0,01\end{array}$ & $\begin{array}{c}r=0,803 \\
p<0,001\end{array}$ \\
\hline Motivation on a certain type of marriage & $r=-0,234$ & - & $p<0,314$ \\
& $p<0,01$ & $r=0,01$ \\
\hline Motivation on the fact of marriage itself & $p<0,003$ & $p<0,001$ & - \\
\hline
\end{tabular}

Thus, aspiration to love and happy family life assumes identification with the spouse, high value of the sexual area, motivation on a certain person, orientation on duty in comparison with pleasure, initiation of conflicts at violation of role expectations and differentiation of qualities of the partner as qualities necessary for marriage and orientation on the traditionally presented romantic love.

The correlation analysis within the component marriage motivation showed the availability of significant negative relationships between all its parameters (Table 1).

So, the parameter motivation on the fact of marriage itself is connected with motivation on a certain type of marriage and motivation on a certain person. The parameter motivation on a certain type of marriage - with motivation on the fact of marriage itself and motivation on a certain person.

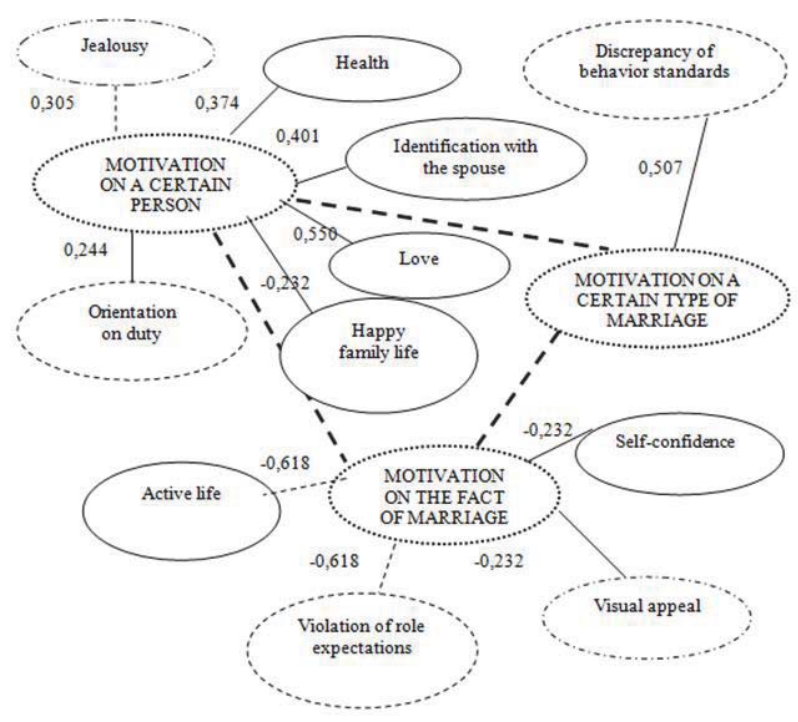

Figure 5. Correlation pleiade of the component "marriage motivation" with other parameters of components of psychological readiness for marriage. 
The parameter motivation on a certain person - with motivation on the fact of marriage itself and motivation on a certain type of marriage. The obtained data allowed drawing a conclusion that when getting married a person is always guided only by one type of motivation (motivation on a certain type of marriage, motivation on a certain person, motivation on the fact of marriage itself) and excludes all other types.

The analysis of correlation relationships of the component marriage motivation, with other components of the model of psychological readiness for marriage allows making some generalizations (Figure 5). So, a person with motivation on a certain type of marriage is self-assured, free and independent in deeds and actions; he considers intimate and sexual area and visual appeal of partners as for each other, and for the surrounding people as an important area of family life. In marital relations the performance of role expectations is important; a marriage partner is considered from the point of view of pleasantness in communication. For people with motivation on a certain person the values are health, love, happy family life, an important area of family life - identification with the spouse. Such people feel responsibility before the marriage partner and are guided, first of all, by duty; they consider a marriage partner from the point of view of the qualities necessary for marriage. In the marriages concluded on the basis of such motivation there are often conflicts because of jealousy.

Let's rest upon the analysis of relationships between the scales within the component of ideas of marital hierarchy (Figure 6). The parameter relation to a traditional role of the woman in a family correlates with the established standards of behavior and disagreements in relation to money. Disagreement parameter in relation to money is positively connected with duty to a family, traditional role of the woman in a family, role expectations and standards of behavior in a family. In general, the obtained data confirm the orientation of people getting married to a traditional type of relations between the spouses.

Each parameter of the component of ideas of marital hierarchy has significant correlation relationships also with other components. The correlation analysis of the parameter violation of role expectations allowed revealing its interrelation with the parameters not only within this component, but also with the parameters of other components of the system of psychological readiness for marriage.

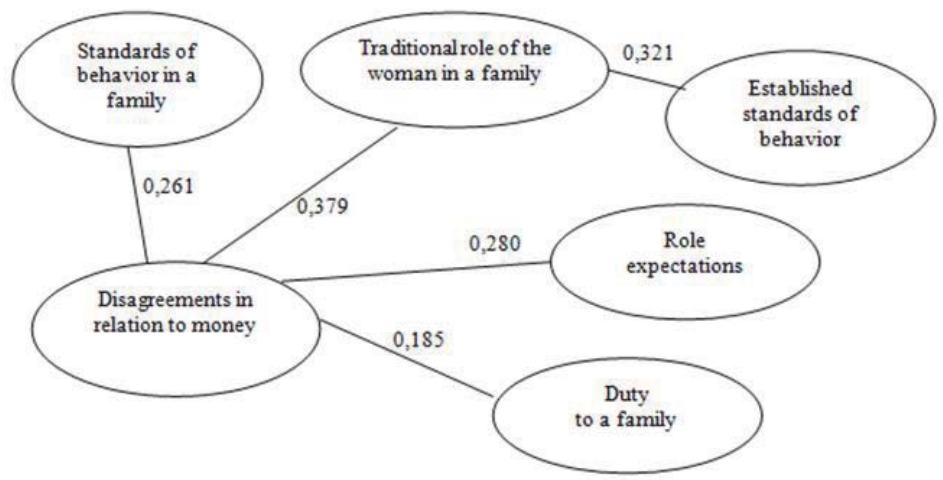

Figure 6. Correlation pleiade of the parameters within the component "ideas of marital hierarchy" of psychological readiness for marriage

The parameter discrepancy of behavior standards is connected by negative correlation relationship with motivation on a certain type of marriage $(r=0,268 ; p<0,01)$, by positive correlation relationship with economic and household $(r=0,258$; $p<0,01)$ and parental and educational $(r=0,299 ; p<0,001)$ life areas of a family, orientation to the traditionally presented romantic love $(r=0,268 ; p<0,01)$, autonomy manifestation by one of the spouses $(r=0,285 ; p<0,001)$, with the selfdescription and the ideal self as a marriage partner by marriage qualities (according to $r=0,239 ; r=0,255 ; p<0,01$; $p<0,01)$, with expectations in economic and household $(r=0,326 ; p<0,001)$, parental and educational $(r=0,249 ; p<0,01)$ and emotional and psychotherapeutic $(r=0,283 ; p<0,001)$ family areas.

Let's analyze the obtained significant correlation relationships of the component marital attitudes and expectations. Let's rest upon the relationships between the scales within the component. Here let's draw attention to the parameter the self-description mainly by the communication qualities, it is interconnected with the self-description as an ideal marriage partner $(r=0,535 ; p<0,001)$, description of a partner and an ideal marriage partner (according to $r=0,223 ; r=0,407$; 
$p<0,01 ; p<0,001)$. Expectations and aspirations in the parental and educational area of a family are connected with the self-description (according to $r=0,483 ; r=0,373 ; p<0,001 ; p<0,001$ ), as an ideal marriage partner (according to $r=$ 0,$448 ; r=0,238 ; p<0,001 ; p<0,01$ ), a marriage partner (according to $r=0,319 ; r=0,232 ; p<0,001 ; p<0,01$ ) and an ideal marriage partner $(r=0,535 ; p<0,001)$ mainly by marriage qualities. In this case orientation to importance of the parental and educational area differentiates its image and the partner's image according to the qualities necessary for performance of this function.

And, finally, let's describe the significant correlation relationships of the component of ideas of marital relations. Here the parameter the relation to autonomy or dependence of the spouses is positively connected with the relation to love of romantic type $(r=0,203 ; p<0,05)$ and it is negatively connected with the relations with relatives and friends and "the offender" in the conflict of the partner (according to $r=-0,375, r=-0,249 ; p<0,001, p<0,01$ ). The parameter autonomy manifestation by one of the spouses is connected with jealousy manifestation $(r=0,276 ; p<0,01)$, with accusation in the conflict both yourself, and the partner (according to $r=0,448, r=0,566 ; p<0,001, p<0,001$ ).

Thus, the higher the orientation of the spouses to joint activity in all areas of family life is, the more apparent the orientation to the traditionally presented romantic love and accusation at the beginning of the conflict of the partner is. To the contrary, the more the autonomy manifestation by one of the spouses is, the more often the conflicts burst because of jealousy and through a fault of both partners.

Significant correlation relationships of this component were revealed also with other components of the system of psychological readiness for marriage. So, the autonomy of one of the spouses corresponds to such life values as selfconfidence $(r=0,196 ; p<0,05)$ and cognition $(r=0,214 ; p<0,01)$, with emergence of the conflicts concerning upbringing of children $(r=0,217 ; p<0,01)$. Such position of the person is connected with the orientation to egalitarian type of marriage $(r$ $=0,224 ; p<0,01)$ and emergence of the conflicts concerning violation of the role expectations $(r=0,319 ; p<0,001)$, violations of behavior standards $(r=0,274 ; p<0,001)$ and relations to money $(r=0,428 ; p<0,001)$. Such person does not expect the emotional and psychotherapeutic assistance $(r=-0,301 ; p<0,001)$ and does not consider necessary to be good-looking for the marriage partner $(r=-0,355 ; p<0,001)$.

After carrying out of the correlation analysis between all parameters of psychological readiness for marriage in both groups, we carried out the comparative analysis of the correlations obtained in matrices in each parameter of the system of psychological readiness for marriage (Figure 7).

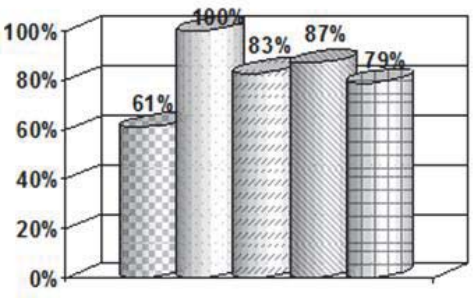

口Ценностые ориентапии

口Брачнаям отивация

口Представления о супружеской иерархии

口Супрукеские установки и ожидания

ФПредставления о супружесих отнотениях

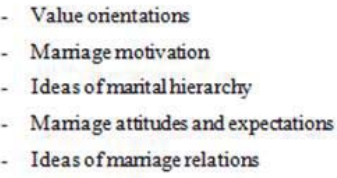

Figure 7. Coincidence of correlation relationships of Group 1 and Group 2

In the course of the comparative analysis of the obtained correlation relationships it was revealed that the number of the coinciding correlation relationships of the system of psychological readiness for marriage between Group 1 and Group 2 make up $77 \%$. As you can see by the Figure, absolute coincidences were obtained only in the parameter "marriage motivation", high level of coincidences was found also in the parameter "marital attitudes and expectations" (87\% of coincidences). At the same time, the lowest number of coincidences was revealed in the parameter "value orientations" (61\%), marital relations (79\%) and "marital hierarchy" (83\%). 
In our opinion, the obtained data allow drawing a conclusion that, namely, in these areas the respondents who are not going to marry in the nearest time have an insufficiently formed psychological readiness for marriage.

At the same time, it should be noted that rather high percent of average value of coincidences of correlation relationships (77\%) confirms that psychological readiness for marriage represents complete personal formation.

\section{Conclusion}

The model of psychological readiness for marriage singled out by us on the basis of the theoretical analysis can be considered empirically proved. Psychological readiness for marriage represents a complete system in which all components (marital values, marriage motivation, ideas of marital hierarchy, marital attitudes and expectations, ideas of marital relations) are interrelated to each other.

Distinctions in the interrelation of correlation relationships between the groups we explain by the fact that psychological readiness for marriage as personal formation can have different level of formation and structural organization of its components.

\section{References}

Aleshina Yu.E., etc. (1978) Social and Psychological Methods of Research of Marital Relations - Moscow.

Aleshina, Yu.E. (1978) Development Cycle of a Family: Researches and Problems: Bulletin of the Moscow University. Series 14. Psychology: Academic Periodical, Edition of the Russian Academy of Sciences and Institute of Psychology of the Russian Academy of Sciences. - No. 2.

Andreeva, T.A. (2007) Psychology of Family: Teaching Aids. - St. Petersburg: Rec. - P. 384 - ISBN 5-9268-0655-0.

Andreeva, T.V. (1985) About Motivation of Work Activity of Architects (Experience of Longitudinal Research): Psychological and Pedagogical Problems of Motivation of Educational and Work Activity. Thesis Report at the Research and Practical Conference, under the editorship of Leontyev V.G. - Novosibirsk.

Andreeva, T.V. (1989) Social and Psychological Factors of Formation of Personality Orientation in the Course of Creative Formation (on the Example of Architects): PhD Thesis in Psychology / Andreeva T.V. - L.: LSU.

Antonyuk, E.V. (1992) Ideas of Spouses of Distribution of Roles and Formation of Role Structure of Young Family: DSc Thesis in Psychology / Antonyuk E.V. - Moscow - 337 pages - P. 41.

Basics of Family Psychology and Family Consultation / Under the general editorship of N.N. Posysoev, Moscow. "VLADOS", 2004 - 328 pages - P. 130-135. - ISBN: 5-305-00113-7.

Chernikov, A.V. (2001) System Family Therapy: Integrative Model of Diagnostics. Moscow. - 208 pages - ISBN: 5-86375-130-4.

Chistyakova, T.Yu. (1989) Life Values and Plans of Unmarried Women. Formation of Marital Relations: Moscow: Pedagogics. - 325 pages.

Eydemiller, E.G., Yustitskis, V. (2002) Psychology and Psychotherapy of Family: St. Petersburg. Piter. - 656 pages - ISBN 5-88782394-1.

Golod, S.I. (1990) Private Life: Love, Gender Relations. - L.

Gozman, L.Ya., Aleshina, Yu.E. (1987) Communication and Development of Relations within Married Couple - Moscow: Publishing House MG.

Grachev, A.A. (1999) Life Orientations as Life Activity Determinants: Psychological Problems of Self-Realization of Personality. - St. Petersburg. - Edition 3.

Ilyin, E.P. (2000) Motivation and Motives. - St. Petersburg: Publishing House "Piter". - 512 pages - ISBN 978-5-272-00028-6.

Kirkpatrick, C. (1955) The Family as Process and Institution. N.Y.

Kovalev, S.V. (1988) Psychology of Modern Family: Information and Resource Materials to the course "Ethics and Psychology of Family Life": Teacher's Book: - Moscow: Prosveshcheniye. - 208 pages.

Kunitsyna, V.N. (2004) Value and Standard System of the Personality: Psychology / Under the editorship of A.A. Krylov. Moscow: Prospect.

Malyarova, N.V. (1981) Motivation of Marriage and Forecast of Psychological Interference: Family and Personality. Theses of Reports. I Under the editorship of A.A. Bodalev. - Moscow. - P. 124-135.

Maslow, A.H. (1970) Motivation and Personality (2nd). N.Y.: Harper and Row.

Melville, K. (1977) Marriage and the Family. N.Y.

Minukhin, S., Fishman, Ch. (1998) Technology of Family Therapy: Moscow.

Moskvicheva, N.L. (2000) Family in the System of Value Orientations of the Student's Personality: Author's PhD Thesis in Psychology / Moskvicheva Natalia Leonidovna. - St. Petersburg: St. Petersburg State University.

Myers, D. (2006) Social Psychology: St. Petersburg.

Oliferovich, N.I., Zinkevich-Kuzemkina, T.A., Velenta, T.F. (2006) Psychology of Family Crises: St. Petersburg: Rech. - 360 pages - P. 36-37. - ISBN: 5-9268-0416-7.

Rokeach, M. (1968) Beliefs, Attitudes and Values. San-Francisco. 463 p. 
Studia Filozoficzne. W-wa, 1981. N 4.

Suslova, T.F. (1999) Personal Determinants of Combination of Professional and Family Roles by Businesswomen: PhD Thesis in Psychology. - Moscow. - 138 pages - P. 48.

Yurkevich, N.G. (1971) Role of the Soviet Family Law in Family Strengthening: Social Researches. Methodological Problems of Life Research. Edition 7. Moscow: Nauka. 